\title{
The best wildflowers for wild bees
}

\author{
Rachel N. Nichols ${ }^{1}\left[\right.$. Dave Goulson ${ }^{1} \cdot$ John M. Holland ${ }^{2}$
}

Received: 31 January 2019 / Accepted: 23 September 2019 / Published online: 28 September 2019

(c) The Author(s) 2019

\begin{abstract}
Governmental agri-environment schemes (AES) aim to improve pollinator abundance and diversity on farmland by sowing wildflower seed mixes. These often contain high proportions of Fabaceae, particularly Trifolium (clovers), which are attractive to some bumblebee species, but not to most of the $\sim 240$ solitary bee species in the UK. Here we identify wildflowers that are attractive to a greater range of wild bee species. Forty-five wildflower species being farmed for commercial seed production on a single farm were surveyed for native bees. Bee walks were conducted through discrete wildflower areas from April until August in 2018. The results indicate that including a range of Apiaceae, Asteraceae, and Geraniaceae in seed mixes would cater for a wide diversity of bee species. A total of 14 wildflower species across nine families attracted 37 out of the 40 bee species recorded on the farm, and accounted for $99.7 \%$ of all visitations. Only two of these 14 species are included in current AES pollinator mixes. Unexpectedly, few visits were made by bumblebees to Trifolium spp. (0.5\%), despite their being considered an important food source for bumblebees, while Anthyllis vulneraria and Geranium pratense were highly attractive. For solitary bees, Crepis capillaris, Sinapsis arvensis, Convolvulus arvensis and Chaerophyllum temulum were amongst the best performing species, none of which are usually included in sown flower mixes. We suggest that the standard 'pollinator' mixes used in AES might be updated to include some of these wildflower species, and trialled as seed mixes on farmland.
\end{abstract}

Keywords Agri-environment scheme $\cdot$ Wildflowers $\cdot$ Solitary bees $\cdot$ Bumblebees $\cdot$ Pollinators $\cdot$ Seed mix

\section{Introduction}

Traditionally, honey bees have been the main or only managed crop pollinator, though there are instances of bumblebees and solitary bees (encompassing all non-corbiculate, non-Bombus wild bee species) being managed for enhancing pollination of specific crops (Gruber et al. 2011; Sheffield 2014; Zhang et al. 2015). However, recent studies have revealed that wild bees play a substantial role in crop pollination. In the UK, it is estimated that honey bees contribute at best $30 \%$ of crop pollination, the remainder

Electronic supplementary material The online version of this article (https://doi.org/10.1007/s10841-019-00180-8) contains supplementary material, which is available to authorized users.

Rachel N. Nichols

R.Nichols@sussex.ac.uk

1 School of Life Sciences, University of Sussex, John Maynard Smith (JMS) Building, Falmer, Brighton BN1 9QG, UK

2 Game and Wildlife Conservation Trust, Burgate Manor, Fordingbridge, Hampshire SP6 1EF, UK being delivered by wild bees (Breeze et al. 2011). Crop yields improve with increased pollinator functional diversity (Hoehn et al. 2008), fruit and seed set improve when wild bees are present (Garibaldi et al. 2013; Campbell et al. 2017), and due to the loose pollen held on body hairs, individual visits by solitary bees often transfer more pollen than visits by honey bees (Woodcock et al. 2013). Additionally, wild bees are important for the pollination of wildflowers (Forup and Memmott 2005; Biesmeijer et al. 2006; Rollin et al. 2016), with some rarer wildflower species relying on specific native bees to ensure their survival (Gibson et al. 2006), and there is evidence that wildflowers might not be adequately pollinated with decreased pollinator abundance (Jacobs et al. 2009). It is therefore vital we maintain our wild bee populations to ensure the continued pollination of our crops and wildflowers.

Insects have been declining at alarming rates over the past century. The biomass of flying insects declined by $76 \%$ on nature reserves in Germany over the past 27 years (Hallmann et al. 2017), and although annual surveys of cereal crops in an area of southern UK reported an overall 
decline in insect abundance of $35 \%$ over 42 years, there was considerable variation between taxa, with some showing increases or no decline (Ewald et al. 2015, 2016). Specifically, the extinction rate of pollinating aculeates has increased significantly since the late nineteenth Century (Ollerton et al. 2014), with wild bees decreasing across $52 \%$ of areas within Britain (Biesmeijer et al. 2006). The Red List for wild bees in Europe (Nieto et al. 2014) estimates that $9.2 \%$ of wild bee species are 'threatened', increasing to over $60 \%$ of species when taking Data Deficient species into consideration, showing just how little data is available for the majority of wild bee species. Of the 77 European species given 'threatened' status, six of these species are native to the UK (Nieto et al. 2014). It is important to understand what is causing these declines so that we can prevent further loss of wild pollinators.

The majority of publications link pollinator and bee declines to various aspects of agricultural intensification, such as loss of flower-rich natural and semi-natural habitat (Biesmeijer et al. 2006), loss of safe nesting locations in close proximity to floral resources (Richards 2001; Goulson 2003), and increased frequency of application of pesticides over the last 80 years (Johansen 1977; Brittain et al. 2010; Goulson et al. 2015, 2018). Farmland makes up a large area of land in the UK ( 70\%), and therefore it needs to be managed in a way to ensure no further loss of pollinator diversity.

To counteract the loss of pollinators on farmland, member states of the European Union (EU) have committed to take nationwide action to address pollinator declines (Underwood et al. 2017) and the UK released its National Pollinator Strategy in 2014 (DEFRA 2014). These are predominantly achieved through agri-environment schemes (AES) as part of the Common Agricultural Policy (CAP). In the UK, the Environmental Stewardship Scheme established in 2005 included 'Nectar flower mixture' (EF4/HF4) and 'Legume rich sward' (EK21/HK21) options. These required a minimum of four and three Fabaceae species to be sown, respectively, forming $80-100 \%$ of the species found in the 'Nectar flower mixture' option, and covering a minimum of $20 \%$ of the sown area in 'Legume rich sward' option (DEFRA 2013a, b). These could be sown in rotating plots or along field margins in exchange for monetary returns. Under the new Countryside Stewardship (CS) scheme which first opened for applications in 2015, the "wild pollinator and farm wildlife package' again includes a list of four suggested Fabaceae species in the 'Nectar flower mix' (AB1) to sow alongside two additional perennial species (DEFRA 2018). These plants chiefly target long-tongued bumblebees (Corbet 2006), and the sowing of these seed mixtures on farms has led to an increase in the abundance of a few common bumblebee species (Wood et al. 2015b). In contrast the commercial wildflower mixes used in Germany, although containing multiple Fabaceae species, are overall more diverse than the typical pollinator mixes used in the UK (Grass et al. 2016; Warzecha et al. 2018).

Fabaceae heavy mixtures, often containing a high proportion of Trifolium spp., are suggested to have been chosen based on an "educated guess" (Williams and Lonsdorf 2018) after typical grazing meadow wildflowers declined. However, these mixes do not cater for the needs of most of the wider native bee species, particularly the $\sim 240$ species of solitary bees. In the UK, only $32 \%$ of solitary bees present on farms visit the wildflowers sown in these mixtures (Wood et al. 2015a), with most visits by solitary bees to Centaurea nigra, Daucus carota, and Leucantheum vulgare, with very few visits to Trifolium spp. (Wood et al. 2017). Seventy three percent of foraging visits by solitary bees were to Asteraceae and Apiaceae found naturally on farmland and which were not part of sown mixes (Wood et al. 2015a). Additional research shows no visits were made by cavity-nesting bees in the UK to flowers sown as part of an AES seed mix (Gresty et al. 2018). This demonstrates that a large proportion of UK bee species are not benefitting directly from 'pollinator' seed mixes, and that there is scope to develop new mixes that cater for the needs of a greater diversity of wild bee species.

Many wildflower seed companies produce seeds of plant species that are not usually included in farmland seed mixes, and for which we do not have robust data on solitary bee visitation. By working with Emorsgate Seeds@ on one of their commercial wildflower farms, we were able to gain access to large stands of wildflower species. Wild bees have been shown to focus their foraging on floral strips of lower species richness (Warzecha et al. 2018) but high floral density (Balzan et al. 2014). Therefore the wildflower stands essentially provided a choice experiment for natural wild bee populations. The majority of previous studies of wild bee visits to wildflowers have recorded bumblebee species but not solitary bees to species level (but see Wood et al. 2015a, 2017; Warzecha et al. 2018; Ouvrard et al. 2018). Here, we identified all bees to species (excluding the Bombus terrestris/lucorum complex). The aim of this project was to determine in an environment where each plant species was very plentiful (i) which cultivated wildflowers attract the greatest number of native bee species; (ii) which wildflower species attract which wild bee species, and therefore (iii) what wildflowers should be considered for inclusion in an improved seed mix intended to cater for a broader suite of bee species.

\section{Methods}

\section{Study site}

The study was conducted in 2018 at Emorsgate Seeds@ Manor Farm, a wildflower crop farm near Bath, UK 
$\left(51^{\circ} 25^{\prime} 46.0^{\prime \prime} \mathrm{N} 2^{\circ} 22^{\prime} 27.7^{\prime \prime} \mathrm{W}\right)$. Wildflower crops were established as segregated wildflower strips of varying width in the clay-based soil from as early as 1999 , with the most recent in 2017. These wildflower crops and weed areas of varying floral diversity were managed in a way to ensure maximum seed harvests without requiring 'clean' crops or using excessive amounts of agrochemicals. Some crops were inter-row sprayed with minimal amounts of industry-standard herbicides and a fungicide to minimise crop losses. Crops, weed strips, field margins and verges were monitored for flowering plant species from April to August, and distinct wildflower patches identified. A total of 31 wildflower transects were selected over the season, each surveyed whilst at their floral peak (at least $60-70 \%$ of plants in flower). Transects were $50 \mathrm{~m}$ in length and walked on two consecutive days (survey round). There were a total of eight survey rounds spread equally from April to August, and these were combined into four survey periods: 20th-21st Apr \& 6th-7th May (Apr-May), 21st-22nd May \& 10th-11th Jun (May-Jun), 22nd-23rd Jun \& 8th-9th Jul (Jun-Jul), and 22nd-23rd Jul \& 8th-9th Aug (Jul-Aug). Some patches were smaller, in which case the transect size was noted. Ideally we would have had replicated equal-sized patches of each plant species, but as this is a commercial operation this was not possible. Surveys were conducted between 08:30 and 17:00 when weather met the UK Butterfly Monitoring Scheme conditions: temperature above $13{ }^{\circ} \mathrm{C}$ with at least $60 \%$ clear sky, or $17^{\circ} \mathrm{C}$ in any sky conditions, and not raining (Pollard and Yates 1993).

\section{Wild bee surveys}

Wild bees were recorded while walking along the $50 \mathrm{~m}$ transect, using standard bee walk protocols as in Carvell et al. (2006). Bees seen foraging on the target plant species within $2 \mathrm{~m}$ of the observer were recorded. Each was identified to species level either in the field or later in the laboratory after netting. Bombus terrestris, B. lucorum, B. cryptarum and B. magnus are impossible to reliably distinguish in the field, and were recorded as Bombus terrestris agg. No distinction was made between individuals foraging for pollen or nectar; and males, workers and queens were pooled together for data analysis.

\section{Floral surveys}

Three random $10 \times 2 \mathrm{~m}$ quadrats of each transect were selected, and number of flowers of each species present were counted within the following ranges as used in Heard et al. (2007): 1-5; 6-25; 26-200; 201-1000; 1001-4999; and $5000+$ flower units (defined as a single flower or an umbel, spike or capitulum on multi-flowered stems). The median flower number of the range was then used to calculate the mean number of flowers for the quadrats and extrapolated for the transect (Heard et al. 2007).

\section{Data analysis}

All data analysis was handled in $\mathrm{R}$ ( $\mathrm{R}$ Core Team 2018). Consecutive survey days were summed together to maximise the number of insects analysed in any one round for analysis, and modelled using the lme 4 package (Bates et al. 2015). Survey rounds were summed together creating survey periods to better visualise the data. A scatter plot was constructed using gplots (Warnes et al. 2016) and heatmaps created using ggplot2 (Wickham 2016).

Wild bee richness and wild bee abundance were analysed separately. Richness was $N+1$ transformed to deal with zero counts causing under-dispersion, and abundance was log $(N+1)$ transformed. Generalised Linear Models were built with the response variable 'bee richness' or 'abundance' and explanatory variables: wildflower species; survey round; wildflower species density per $\mathrm{m}^{2}$; transect floral richness; and transect size (no interactions). Stepwise removal of non-significant explanatory variables was conducted, AIC values were compared, and plot diagnostics of residuals of the final model were checked. For both bee richness and bee abundance, only 'wildflower species' and 'survey period' as explanatory variables were included in the final model. Poisson distribution with log link was used for both models. An ANOVA Chi squared test of each model was conducted to determine significance of explanatory variables.

Visitation records for each wildflower species were pooled by bee group (bumblebee or solitary bee), and bee richness against bee abundance was plotted. We built a Linear Model of 'bee richness' explained by 'bee abundance $(\log N+1)$ ' and 'bee group' to assess the fit of the plot. Solitary bees and bumblebees were then modelled separately to get the regression line statistics for each group. Plot diagnostics of residuals were checked for each model.

\section{Results}

Surveys were conducted on 31 different wildflower transects, incorporating a total of 45 plant species that were specifically observed for wild bee visits. The wildflower transects were across seven adjoining fields and two roadside verges (Supplementary Information-S1). During wildflower surveys, 1691 wild bees were recorded foraging, encompassing 40 different species. Of these, solitary bees comprised 202 visits by 32 different species, and bumblebees comprised 1489 visits by six true social bumblebee species and two parasitic Psithyrus spp. (Supplementary Information-S2).

Some bee species were seen more regularly than others (Supplementary Information-S3). Bombus lapidarius was 
highly abundant and made up $54.8 \%$ of total wild bee visitation and $62.3 \%$ of bumblebee visitations, with the next most abundant bumblebee (B. terrestris agg.) comprising only $12.4 \%$ of Bombus visits. Of the ten genera of solitary bees seen, Andrena spp. had the highest abundance, comprising $59.4 \%$ of all solitary bee visits. Lasioglossum spp. were the next most abundant, making up $23.8 \%$ of all solitary bee visits. Multiple genera were represented by a single species, included Anthophora plumipes (6.9\% of solitary bee visits) and Halictus tumulorum (5.0\% of visits). Eleven species in total were recorded only once.

\section{Wildflowers attracting greatest diversity of bees}

Of the 45 wildflowers surveyed, solitary bees were found on 30 species across 14 families, and bumblebees found on 27 species across 13 families. Five wildflowers, Silene vulgaris, Geranium lucidium, Veronica chamaedrys, Ranunculus acris, and Viola arvensis, were not visited by any bees during the surveys.

Overall, a wide variety of wildflowers were visited by high numbers of wild bee species, with a statistically significant difference in wild bee richness observed between wildflower species (GLM: $\mathrm{X}^{2}=74.49$, d.f. $\left.=44, \mathrm{P}=0.003\right)$. All wild bee visitations to wildflowers over the season were pooled and wildflowers ranked in order of bee richness (Table 1). The top 14 wildflowers were visited by 37 out of the 40 wild bee species recorded and received $99.7 \%$ of all visitations (Supplementary Information-S4). The top wildflower species for maximum wild bee richness include the Asteraceae Crepis capillaris and Taraxacum agg., along with two Geraniaceae (G. pratense and G. pyrenaicum), followed closely by Convolvulus arvensis and Centaurea scabiosa. The only bee species not visiting these 14 plant species were Colletes daviesanus, Melitta haemorrhoidalis, and Nomada flavoguttata.

Wild bee abundance differed greatly between wildflower species (Table 1) $\left(G L M: \mathrm{X}^{2}=75.633\right.$, d.f. $\left.=44, \mathrm{P}=0.002\right)$. High numbers of bumblebees were seen during the surveys, obscuring the solitary bee visitation data, and so the two groups are considered separately. Plotting bee richness against abundance for each bee group shows there is a positive correlation, as wildflowers with high abundance of bee visitors were also visited by more species (Fig. 1). Overall, the linear model provided a good fit to the data $\left(\mathrm{F}_{2,87}=89.72, \mathrm{P}<0.001\right.$, adjusted $\left.\mathrm{R}^{2}=0.67\right)$. Solitary bees appear to reach a greater number of species at lower abundances (slope estimate: 1.94, $\mathrm{SE}=0.15)\left(\mathrm{F}_{1,43}=175.8\right.$, $\mathrm{P}<0.001$, adjusted $\mathrm{R}^{2}=0.799$ ) than bumblebees (slope estimate: $0.83, \mathrm{SE}=0.07)\left(\mathrm{F}_{1,43}=143.7, \mathrm{P}<0.001\right.$, adjusted $\left.\mathrm{R}^{2}=0.764\right)$. Visualised in this manner, the top wildflower species for solitary bees and bumblebees in both terms of richness and abundance can be identified for each group, and tabulated separately (Table 2).

Although the species lists are of similar length for each bee group, only Crepis capillaris, Taraxacum agg., and
Table 1 Highest ranking wildflower species for wild bee richness over the season

\begin{tabular}{|c|c|c|c|c|}
\hline Period & Wildflower family & Wildflower species & $\begin{array}{l}\text { Wild bee rich- } \\
\text { ness }\end{array}$ & $\begin{array}{l}\text { Wild bee } \\
\text { abundance }\end{array}$ \\
\hline 2,3 & Asteraceae & Crepis capillaris $^{\mathrm{a}}$ & 11.0 & 115.0 \\
\hline 1,2 & Asteraceae & Taraxacum agg. ${ }^{\text {ab }}$ & 10.0 & 21.0 \\
\hline 2,3 & Geraniaceae & Geranium pratense ${ }^{\mathrm{b}}$ & 10.0 & 172.0 \\
\hline 2 & Geraniaceae & Geranium pyrenaicum & 10.0 & 17.0 \\
\hline 4 & Convolvulaceae & Convolvulus arvensis ${ }^{\mathrm{a}}$ & 9.0 & 40.0 \\
\hline $2,3,4$ & Asteraceae & Centaurea scabiosa $^{\mathrm{b}}$ & 8.0 & 426.0 \\
\hline 3,4 & Apiaceae & Daucus carota ${ }^{\mathrm{bc}}$ & 7.0 & 10.0 \\
\hline 3 & Asteraceae & Sonchus arvensis ${ }^{\mathrm{a}}$ & 7.0 & 27.0 \\
\hline $1,2,4$ & Brassicaceae & Sinapsis arvensis $^{\mathrm{a}}$ & 7.0 & 14.0 \\
\hline 3,4 & Lamiaceae & Origanum vulgare ${ }^{\mathrm{b}}$ & 7.0 & 142.0 \\
\hline 1 & Primulaceae & Primula vulgaris & 7.0 & 21.0 \\
\hline 2 & Apiaceae & Chaerophyllum temulum & 6.0 & 33.0 \\
\hline 2,3 & Fabaceae & Anthyllis vulneraria ${ }^{\mathrm{b}}$ & 6.0 & 204.0 \\
\hline $2,3,4$ & Papaveraceae & Papaver rhoeas ${ }^{\mathrm{b}}$ & 5.0 & 55.0 \\
\hline
\end{tabular}

Wild bee visitations to wildflowers over the season were pooled. Wildflowers were then ranked in order of bee richness creating a species list of 14 top-ranking wildflowers for the whole season. Total bee abundance records for wildflowers also shown. Period indicates which survey period(s) the wildflower was surveyed: 1 = Apr-May, 2 = May-Jun, $3=$ Jun-Jul, 4 = Jul-Aug

aWildflower typically considered undesirable or "weeds" (Hicks et al. 2016)

${ }^{\mathrm{b}}$ Included in commercial pollinator mixes

${ }^{\mathrm{c}}$ Included in government recommended mixes (Supplementary Information—S5) 


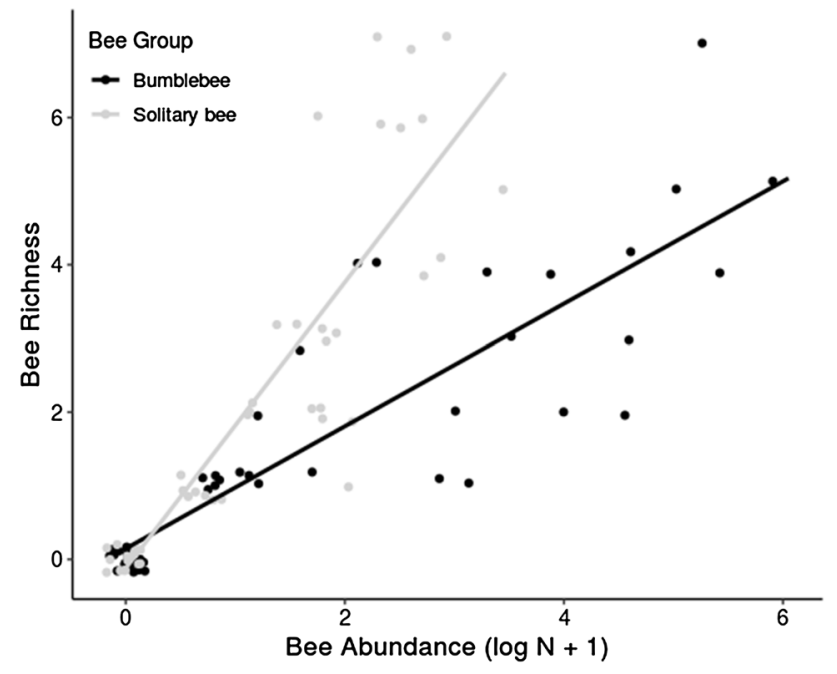

Fig. 1 Wild bee richness against abundance. Bee richness plotted against $\log$ bee abundance $(N+1)$ for each wildflower surveyed for each bee group and regression lines fitted. Bumblebees = black, solitary bees = grey (created in ggplot 2 using jitter positioning to avoid point overlap)

Geranium pyrenaicum are seen in both, and the family diversity of wildflowers varies between both lists.

This list of 16 wildflowers again encompasses 37 out of 40 wild bee species, but only $78.8 \%$ of all visitations, the same species unaccounted for as before. Eleven bee species were recorded only once, and nine wildflowers were visited only once. To cater for the widest range of wild bees these scarcer bees would need to be taken into account. Inclusion of Campanula rotundifolia and
Tripleurospermum inodorum in either wildflower list (Tables 1,2) would result in maximum wild bee richness.

Although survey period had no significant effect on overall wild bee richness (GLM: $\mathrm{X}^{2}=6.117$, d.f. $=7, \mathrm{P}=0.526$ ) or abundance $\left(G L M: \mathrm{X}^{2}=4.64\right.$, d.f. $\left.=7, \mathrm{P}=0.704\right)$, the importance of different wildflowers during each survey period is apparent (Fig. 2), as solitary bees and bumblebees visiting each plant species show markedly different temporal patterns. During Apr-May, Sinapsis arvensis appeared to be particularly important to solitary bees, whereas Taraxacum agg. and Primula vulgaris appear to have equal importance for solitary bees and bumblebees. In May-Jun, there were three Apiaceae species available that solitary bees were foraging from, however, it is clear that Chaerophyllum temulum and Conopodium majus attracted more species than Anthriscus sylvestris, despite the latter being in flower for longer. Throughout May-Jun and Jun-Jul, various Apiaceae and Asteraceae species appeared to play an important role in supporting solitary bee richness, along with Geranium pyrenaicum. However, bumblebee richness was highest on G. pratense. Additionally, there were five Fabaceae species available that bumblebees were foraging from, with Anthyllis vulneraria being visited by the most species and individuals. Finally, during Jul-Aug, Convolvulus arvensis was very important for solitary bee richness and abundance, while the bumblebees were mostly attracted to Centaurea scabiosa and Origanum vulgare at this time. Another element to note is the flowering periods of certain species. Centaurea scabiosa was flowering from May to Jun right through to JulAug, and its importance for bumblebee richness gradually increased during the season. Papaver rhoeas was flowering for a similar length of time, but its importance for solitary
Table 2 Comparing highest ranking wildflowers over the season for solitary bees and bumblebees

\begin{tabular}{|c|c|c|c|c|c|}
\hline \multicolumn{3}{|l|}{ Solitary bees } & \multicolumn{3}{|l|}{ Bumblebees } \\
\hline Wildflower & Richness & Abundance & Wildflower & Richness & Abundance \\
\hline Crepis capillaris $^{\mathrm{a}}$ & 7.0 & 10.0 & Geranium pratense $\mathrm{b}^{\mathrm{b}}$ & 7.0 & 169.0 \\
\hline Sinapsis arvensis ${ }^{\mathrm{a}}$ & 7.0 & 14.0 & Centaurea scabiosa $^{\mathrm{b}}$ & 5.0 & 423.0 \\
\hline Convolvulus arvensis ${ }^{\mathrm{a}}$ & 7.0 & 18.0 & Origanum vulgare & 5.0 & 138.0 \\
\hline Daucus carota ${ }^{\mathrm{bc}}$ & 6.0 & 9.0 & Crepis capillaris $^{\mathrm{a}}$ & 4.0 & 105.0 \\
\hline Sonchus arvensis ${ }^{\mathrm{a}}$ & 6.0 & 10.0 & Leontodon hispidus & 4.0 & 53.0 \\
\hline Taraxacum agg. ${ }^{\mathrm{ab}}$ & 6.0 & 13.0 & Taraxacum agg. ${ }^{\mathrm{ab}}$ & 4.0 & 8.0 \\
\hline Geranium pyrenaicum & 6.0 & 6.0 & Anthyllis vulneraria ${ }^{\mathrm{b}}$ & 4.0 & 202.0 \\
\hline Chaerophyllum temulum & 5.0 & 31.0 & Geranium pyrenaicum & 4.0 & 11.0 \\
\hline Conopodium majus & 4.0 & 14.0 & Malva moschata & 4.0 & 24.0 \\
\hline Primula vulgaris & 4.0 & 17.0 & & & \\
\hline
\end{tabular}

Wild bee visitations to wildflowers over the season were pooled individually for bumblebees and solitary bees. Wildflowers were then ranked in order of bee richness creating a species list of 16 different top-ranking wildflowers, ten for solitary bees, nine for bumblebees, with three found in both groups

aWildflower typically considered undesirable or "weeds" (Hicks et al. 2016)

${ }^{\mathrm{b}}$ Included in commercial pollinator mixes

${ }^{\mathrm{c}}$ Included in government recommended mixes (Supplementary Information—S5) 


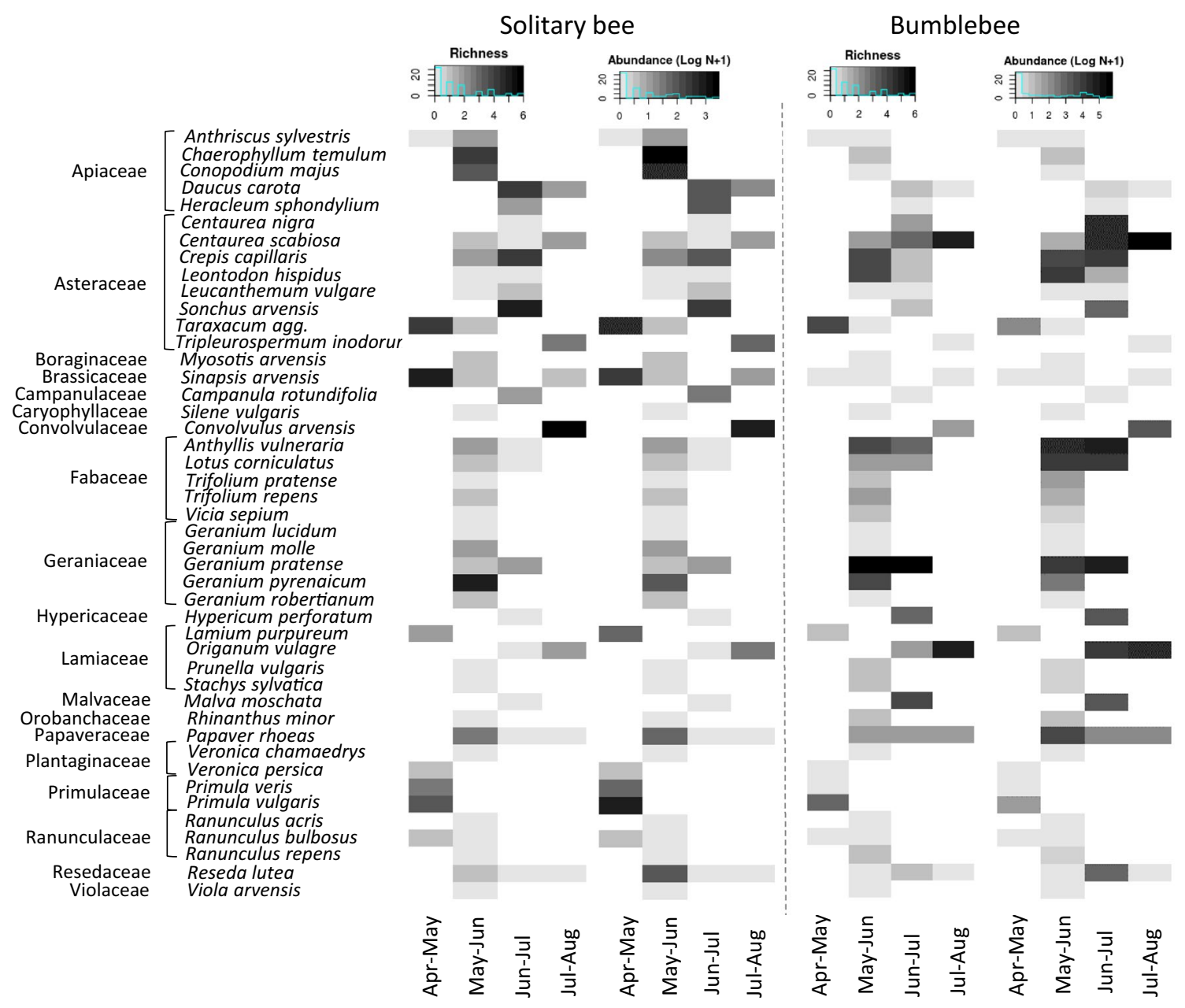

Fig. 2 Comparison of solitary bee and bumblebee species richness and abundance for each wildflower species per survey period. Squares where no survey took place are white. Richness and abundance are

bee richness came early on in the season, whereas the number of bumblebee species it attracted remained approximately constant over the season.

\section{Species-specific attraction to different wildflowers}

Separating visitation data by bee group to different wildflowers (Fig. 2) and families (Supplementary InformationS6) reveals how much these differ between the bee groups. However, separating wild bee visitations down to species level ensures no species-specific preferences are overlooked (Fig. 3).

\section{Bumblebees}

Bombus lapidarius and B. terrestris agg. visited a great range of wildflower species, 18 and 17 respectively, with most visits to Centaurea scabiosa $(38.3 \%$ and $26.6 \%$ of visits respectively). Bombus lapidarius and B. terrestris shown from light grey as zero, to black. Abundance was $\log N+1$ transformed to better visualise. Heatmap style copied from Ouvrard et al. (2018)

agg. were the only bees recorded on Centaurea nigra, which received only $6.0 \%$ of all Bombus visits in comparison to $28.4 \%$ of Bombus visits to C. scabiosa. Bombus terrestris agg. were also observed in high numbers on Origanum vulgare (26.1\% of visits). In strong contrast, $B$. hortorum showed reduced variability, as $98.5 \%$ of its visits were to Anthyllus vulneraria. Likewise, B. pascuorum favoured $A$. vulneraria, with $42.6 \%$ of visits. Bombus pascuorum was also the only bumblebee to visit at least four out of the five Fabaceae species surveyed. Anthyllus vulneraria received $13.6 \%$ of total Bombus visits, and Lotus corniculatus received $7.1 \%$. Trifolium pratense and $T$. repens received only $0.5 \%$ of Bombus visits combined. Bombus pratorum and B. hypnorum were seen most regularly on Geranium pratense $(87.3 \%$ and $48.3 \%$ of visits respectively). Therefore the list of wildflowers important to bumblebees (Table 2) encompasses the most significant wildflower for each of the bumblebees we recorded during surveys. 

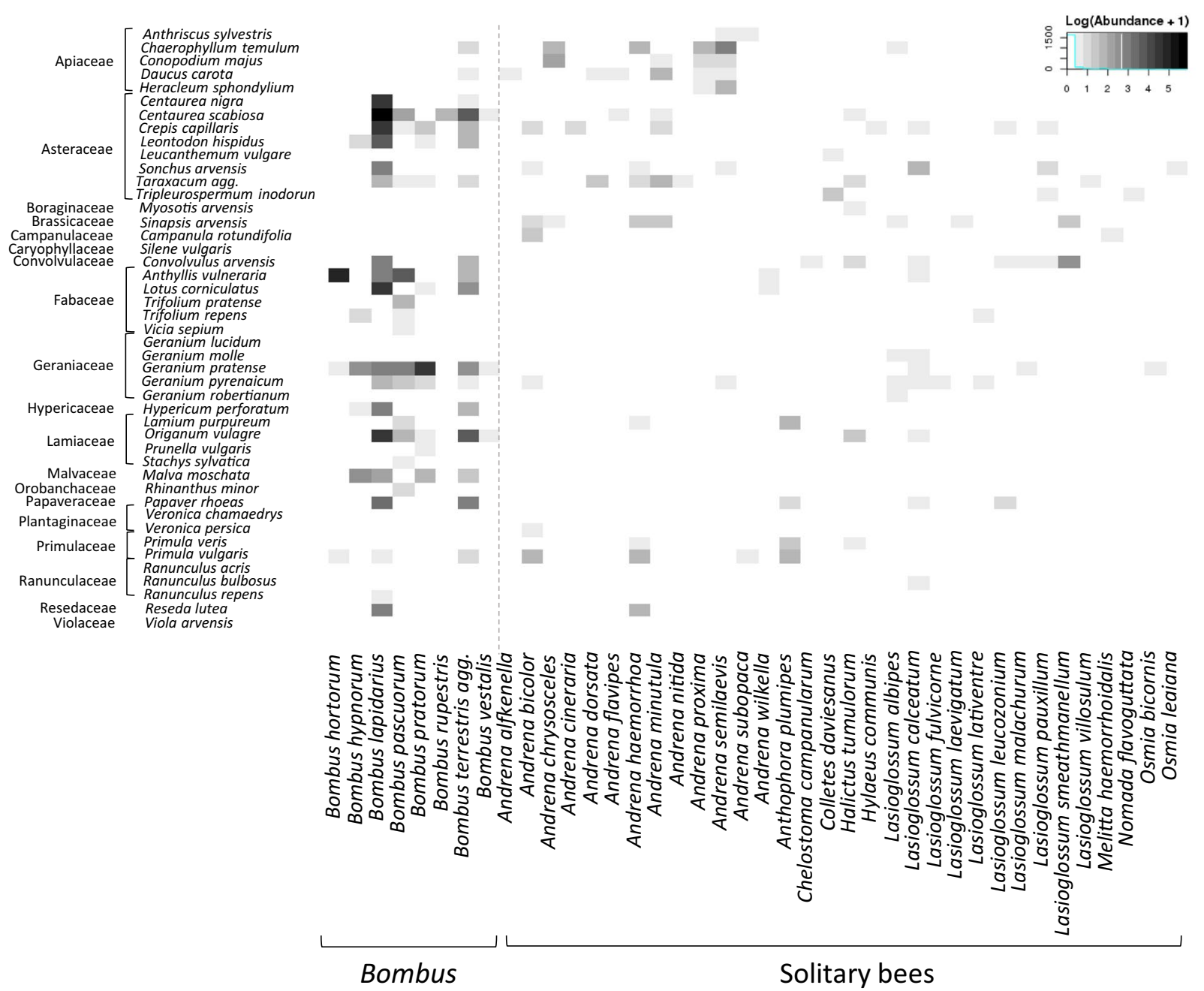

Fig. 3 Abundance visitation matrix. Heatmap showing abundance of all wild bee species to all wildflowers. Instances where a wild bee was seen on a flower are block coloured along a gradient of abundance $(\log N+1)$

\section{Solitary bees}

The majority of Andrena spp. visits (69.2\%) fell within just two families, the Apiaceae and Asteraceae $(51.7 \%$ and 15.5\% respectively). Only Andrena wilkella was not seen on either family, foraging solely on Fabaceae (Anthyllus vulneraria and Lotus corniculatus). Andrena haemorrhoa and A. bicolor had the most diverse foraging ranges, recorded on eight and seven different wildflower species respectively, and across six flower families, recorded in high numbers on Primula vulgaris $21.7 \%$ and $37.5 \%$ respectively). Although Daucus carota received higher Andrena spp. richness (6/13) than Chaerophyllum temulum (4/13), the latter had more Andrena spp. visits overall (14.5\% and $51.6 \%$ respectively). Taraxacum agg. were the key Asteraceae species for Andrena spp., attracting 47.6\% of Andrena visits to this plant family.
Unlike Andrena spp., Lasioglossum spp. had greatest number of visits to Convolvulus arvensis (31.3\%), Asteraceae (22.9\%), and Geraniaceae (18.8\%). Sonchus arvensis received the greatest percentage $(55.6 \%)$ of Lasioglossum visits to Asteraceae. Lasioglossum calcaetum was observed to be the most diverse in its foraging, both within Lasioglossum and all solitary bees, recorded on ten different wildflower species, across seven different families. Finally, Sinapsis arvensis is also important to note, as it received $10.4 \%$ of Lasioglossum visits.

Halictus tumulorum was the sole Halictus spp. to be recorded, and visited six different wildflower species, with the majority of visits to Taraxacum agg. and Origanum vulgare. Anthophora plumipes was one of the earliest flying solitary bees, and ideally requires Primulaceae $57.1 \%$ of visits) or Lamium purpureum (28.6\% of visits) to meet its foraging requirements. Additional solitary bees were not 
recorded regularly, and it would be difficult to make generalisations about their foraging habits based on these low numbers, however, overall they were found to be foraging predominantly on Asteraceae (66.7\% of visits).

\section{Optimal wildflower seed mixture}

Using wildflowers found to be important for both richness and abundance of solitary bees and bumblebees (Tables 1 , 2), as well as wildflowers to achieve total bee richness, it is possible to create a suggested wildflower mix (Table 3). The wildflower species currently suggested by DEFRA are markedly different from those we found to be important, both for solitary bees and for bumblebees, with only two species overlapping with our own mix.

\section{Discussion}

This study differs somewhat from traditional seed mix trials which contain plots of diverse mixes (Carvell et al. 2007; Uyttenbroeck et al. 2017; Warzecha et al. 2018), or farmland transect walks around field margins (Wood et al. 2015a, 2017). The majority of transects in this study had very low levels of plant diversity, and relatively high floral density due to the crop-like manner in which the plant species were established and managed. This essentially provided a choice experiment as wild bees were able to select their "preferred" species to forage from, given a wide choice of high density blocks.

Out of the 40 different wildflower species visited by wild bees, only 14 species from nine families attracted $99.7 \%$ of visits, and $92.5 \%$ of bee species (Table 1). The final list of 18 recommended wildflowers (Table 3 ) was sufficient to provide forage for $100.0 \%$ bee species observed. This finding is similar to Warzecha et al. (2018), who found a minimum of 14 wildflower species across seven families could achieve maximum wild pollinator diversity in Germany. Both studies agree that a range of Asteraceae species were vital for wild bee diversity, however, only Daucus carota appeared in both top 14 plant species lists. This shows that not all regional plant species are required in a seed mix, but just 14-18 key species could create a suitable mix that supports the full diversity of local wild bee populations. Of course there are many other species of pollinator beyond bees, and further research is needed to investigate how best to cater for all of their needs.

\section{Bumblebees}

Bumblebee targeting seed mixes have historically composed of Fabaceae in the UK (particularly Trifolium spp. and Lotus corniculatus). However, our findings raise questions as to whether these are the best species for bumblebees. Not

Table 3 Comparison of recommended wildflowers

\begin{tabular}{lll}
\hline Wildflowers for maximum wild bee diversity (our study) & AB1: nectar flower mix & AB8: flower-rich margins and plots \\
\hline Anthyllis vulneraria (Kidney vetch) & Centaurea nigra & Achillea millefolium \\
Campanula rotundifolia (Harebell) & Lotus corniculatus & Centaurea nigra \\
Centaurea scabiosa (Greater knapweed) & Malva moschata & Daucus carota \\
Chaerophyllum temulum (Rough chervil) & Onobrychis viciifolia & Leaucanthemum vulgare \\
Conopodium majus (Pignut) & Trifolium hybridum & Lotus corniculatus \\
Convolvulus arvensis (Bindweed) & Trifolium pratense & Plantago lanceolata \\
Crepis capillaris (Smooth hawksbeard) & & Prunella vulgaris \\
Daucus carota (Wild carrot) & & Ranunculus acris \\
Geranium pratense (Meadow cranesbill) & & Rhinanthus minor \\
Geranium pyrenaicum (Hedgerow cranesbill) & & Rumex Acetosa \\
Malva moschata (Musk mallow) & & \\
Origanum vulgare (Wild marjoram) & & \\
Papaver rhoeas (Poppy) & & \\
Primula vulgaris (Primrose) & & \\
Sinapsis arvensis (Charlock) & & \\
Sonchus arvensis (Perennial sow-thistle) & & \\
Taraxacum agg. (Dandelion) & & \\
Tripleurospermum inodorum (Scentless mayweed) & &
\end{tabular}

The lists of wildflowers suggested by DEFRA (AB1 and AB8) for wildflower areas designed to target pollinators in comparison to the wildflowers found by this study to maximise wild bee diversity. Flowers in bold are found across more than one list. List from our study contains the 14 top-ranking wildflowers (Table 1), plus additional species noted in Table 2, and those noted to ensure maximum wild bee diversity 
only were Asteraceae and Geraniaceae species the highest ranking for bumblebee richness and abundance, but only one Fabaceae, Anthyllis vulneraria, was in our top-ranking lists, a species not typically found in recommended mixes. Previous work found bumblebee richness and abundance to be highest in sown Fabaceae patches (Carvell et al. 2007). Trifolium species are not particularly rewarding in terms of nectar sugar content, but the pollen of Fabaceae is relatively rich in protein (Hanley et al. 2008), and it has been argued that this explains why they are popular with many bumblebees (Goulson et al. 2008). However, our findings suggest that, when other wildflower species are available in suitable densities, bumblebees would rather forage from these.

Wildflowers noted as being particularly important for bumblebee richness and abundance were Geranium pratense and Centaurea scabiosa. Neither are required in the current AES pollinator mixes (AB1 and AB8) (DEFRA 2018), however, they are occasionally included in other commercial mixes (Supplementary Information-S5). In contrast, Centaurea nigra is often the recommended perennial to add to wildflower mixes to ensure their continued bloom year on year (DEFRA 2018), but it never appeared in any of the top-ranking wildflower lists from our study. Not only is $C$. scabiosa a very similar Asteraceae, but it was visited by more species and individuals overall, it also has a longer flowering time. It might therefore make sense to consider including C. scabiosa in a pollinator mix, as it may attract additional pollinating species besides just wild bees.

A number of wildflowers we found to be important for bumblebees could easily be sown or added into mixes. Few were regarded as undesirable weeds (Table 2) and at least half are already regularly found in seed mixes provided by varying companies (S5) (Geranium pratense, Centaurea scabiosa, Origanus vulgare, Crepis capillaris, Leontodon hispidus, Taraxacum agg., Anthyllis vulneraria, Geranium pyrenaicum, Malva moschata).

\section{Solitary bees}

Ten wildflower species across six families were highlighted as being important for optimum solitary bee richness (Table 2), in particular Apiaceae and Asteraceae species. Asteraceae were shown to be vital for multiple genera and species of solitary bees, with a total of $20.8 \%$ of solitary bee visitations to Asteraceae species. Although Andrena spp. showed a particular liking for Apiaceae, only Daucus carota has been previously used or recommended as a wildflower sown in seed mixes (Wood et al. 2015a, 2017; DEFRA 2018). Apiaceae such as Anthriscus sylvestris and Chaerophyllum temulum are often naturally found on farmland (Wood et al. 2017), so typically might not be included in a seed mix. However, our study shows that at least two or three different Apiaceae are required to support solitary bees.

Roughly half of the species we have suggested for solitary bees are considered "weeds" and wouldn't typically be included in seed mixes, despite having some of the highest amounts of pollen and/or nectar in wildflowers (Hicks et al. 2016). For example, we suggest species such as Taraxacum agg., Crepis capillaris, and Tripleurospermum inodorum, all of which are rarely suggested for seed mixes, despite having high levels of pollen (Hicks et al. 2016). Our study reiterates previous research that suggests typical seed mixes rarely support wider bee fauna (Carvell et al. 2007; Balzan et al. 2014), and the importance of weeds and surrounding landscape flora for supporting solitary bees (Scheper et al. 2015; Wood et al. 2017; Sutter et al. 2017).

As with bumblebees, many wildflowers which are widely visited by bees in farmland were not preferred by bees in this study. For example, Wood et al. (2017) found that Leucanthemum vulgare and Heracleum sphondyllium received many solitary bee visits. In contrast, during our study these wildflowers had very few solitary bees observed foraging on them with Leucanthemum vulgare having only one recorded visiting solitary bee throughout the whole summer season. Wood et al. (2017) showed that as the proportion of flowering units of plant species sown as part of pollinator friendly management increased, so did the proportion of pollen visits be solitary bees. This suggests that they make use of whatever is most abundant, even if it is not their "preferred" foraging source.

Finally, the flight seasons of solitary bees should be taken into consideration when formulating a seed mixture. Many species have a relatively short flight season, some with a second generation that utilises an alternative foraging source to the first generation (Falk and Lewington 2015). Therefore, wildflowers must be selected that will flower during different months, with maximum coverage throughout the year. In particular, mixes that specifically contain earlier flower plants have previously been found to be more attractive to wild pollinators (Dicks et al. 2015; Wood et al. 2017).

\section{Conclusions}

We identify a relatively small number of wildflower species that are highly attractive to a broad range of bee species when bees are given a wide choice of flowers at high density. Interestingly, most of these species are not currently included in standard "pollinator" mixes, while the wildflowers that are included did not fare particularly well in our study. Overall, this suggests that there is scope for improvement of the seed mixes recommended to farmers and that seed mixes could be better tailored to attract a wider range of pollinators or to serve a more specific purpose. Flowering 
times should also be taken into consideration so that nectar flower mixes do not detract bees from crop pollination. However, it should be noted that some of the species that performed well in our study are weeds which might create agronomic difficulties. For example, Sinapsis arvensis is a serious weed of oilseed rape crops. It is unknown how well the species which were most attractive to bees in our study would perform when sown in mixtures on farmland.

We suggest that there is a need to trial mixtures containing these species alongside the current recommended wildflower mixes. This would show us how well the seed mixes establish in comparison to the current mixes, how well they provided forage throughout the year and over the years, whether any of these plant species would cause significant agronomic problems for farmers, and if any species are particularly dominant and out-compete the others.

We focus here on bees, but there are many other flowervisiting insects, such as Syrphidae, Lepidoptera, various wasps, beetles and many others which we should not forget. We are currently trialling wildflower mixes based on this study, aiming to fill some of these knowledge gaps, and determine the attractiveness of these mixes to other wild pollinators as well as native bees.

Acknowledgements The author would like to thank Donald Macintyre and Jane Lipington (Emorsgate Seeds@) for their hospitality at Manor Farm, and Steven Falk for verifying identification of bee specimens.

Funding R.N.N was funded by a NERC CASE studentship (NE/ P009972/1) with additional support from The Game and Wildlife Conservation Trust.

Data statement The data that support the findings of this study are openly available at Sussex Research Data Repository https://doi. org/10.25377/sussex.9911288

\section{Compliance with ethical standards}

Conflict of interest The authors declare no competing interests. Emorsgate Seeds@ had no role in the study design, data collection and analysis, or writing of the paper.

Ethical approval This study received ethical approval from the University of Sussex Animal Welfare and Ethical Review Body (ARG/11/01).

Open Access This article is distributed under the terms of the Creative Commons Attribution 4.0 International License (http://creativeco mmons.org/licenses/by/4.0/), which permits unrestricted use, distribution, and reproduction in any medium, provided you give appropriate credit to the original author(s) and the source, provide a link to the Creative Commons license, and indicate if changes were made.

\section{References}

Balzan MV, Bocci G, Moonen A-C (2014) Augmenting flower trait diversity in wildflower strips to optimise the conservation of arthropod functional groups for multiple agroecosystem services. J Insect Conserv 18:713-728. https://doi.org/10.1007/s1084 1-014-9680-2

Bates D, Maechler M, Bolker B, Walker S (2015) Fitting linear mixedeffects models using lme4. J Stat Softw 67:1-48. https://doi. org/10.18637/jss.v067.i01

Biesmeijer JC, Roberts SPM, Reemer M et al (2006) Parallel declines in pollinators and insect-pollinated plants in Britain and the Netherlands. Science 313:351-354. https://doi.org/10.1126/scien ce. 1127863

Breeze TD, Bailey AP, Balcombe KG, Potts SG (2011) Pollination services in the UK: how important are honeybees? Agric Ecosyst Environ 142:137-143. https://doi.org/10.1016/J. AGEE.2011.03.020

Brittain CA, Vighi M, Bommarco R et al (2010) Impacts of a pesticide on pollinator species richness at different spatial scales. Basic Appl Ecol 11:106-115. https://doi.org/10.1016/J. BAAE.2009.11.007

Campbell AJ, Wilby A, Sutton P, Wäckers FL (2017) Do sown flower strips boost wild pollinator abundance and pollination services in a spring-flowering crop? A case study from UK cider apple orchards. Agric Ecosyst Environ 239:20-29. https://doi. org/10.1016/J.AGEE.2017.01.005

Carvell C, Westrich P, Meek WR et al (2006) Assessing the value of annual and perennial forage mixtures for bumblebees by direct observation and pollen analysis. Apidologie 37:326-340. https:// doi.org/10.1051/apido:2006002

Carvell C, Meek WR, Pywell RF et al (2007) Comparing the efficacy of agri-environment schemes to enhance bumble bee abundance and diversity on arable field margins. J Appl Ecol 44:29-40. https ://doi.org/10.1111/j.1365-2664.2006.01249.x

Corbet SA (2006) A typology of pollination systems: implications for crop management and the conservation of wild plants. In: Waser NM, Ollerton J (eds) Plant-pollinator interactions: from specialization to generalization. University of Chicago Press, Chicago

DEFRA (2013a) Entry level stewardship environmental stewardship handbook. www.naturalengland.org.uk. Accessed 25 Oct 2018

DEFRA (2013b) Higher level stewardship environmental stewardship handbook. www.naturalengland.org.uk. Accessed 25 Oct 2018

DEFRA (2014) The National Pollinator Strategy: for bees and other pollinators in England. Defra Publ. PB14221. https://www.gov. uk/government/publications/national-pollinator-strategy-for-beesand-other-pollinators-in-england. Accessed 28 Jan 2019

DEFRA (2018) Countryside stewardship: mid tier and new CS offers for wildlife manual. www.gov.uk/countrysidestewardship. Accessed 25 Oct 2018

Dicks LV, Baude M, Roberts SPM et al (2015) How much flower-rich habitat is enough for wild pollinators? Answering a key policy question with incomplete knowledge. Ecol Entomol 40:22-35. https://doi.org/10.1111/een.12226

Ewald JA, Wheatley CJ, Aebischer NJ et al (2015) Influences of extreme weather, climate and pesticide use on invertebrates in cereal fields over 42 years. Glob Chang Biol 21:3931-3950. https ://doi.org/10.1111/gcb.13026 
Ewald JA, Wheatley CJ, Aebischer NJ et al (2016) Investigation of the impact of changes in pesticide use on invertebrate populations. Natural England, York

Falk SJ, Lewington R (2015) Field guide to the bees of Great Britain and Ireland. Bloomsbury Publishing Plc, London, First

Forup ML, Memmott J (2005) The restoration of plant-pollinator interactions in Hay Meadows. Restor Ecol 13:265-274. https://doi. org/10.1111/j.1526-100X.2005.00034.x

Garibaldi LA, Steffan-Dewenter I, Winfree R et al (2013) Wild pollinators enhance fruit set of crops regardless of honey bee abundance. Science 339:1608-1611. https://doi.org/10.1126/science.1230200

Gibson RH, Nelson IL, Hopkins GW et al (2006) Pollinator webs, plant communities and the conservation of rare plants: arable weeds as a case study. J Appl Ecol 43:246-257. https://doi.org/10.111 $1 / \mathrm{j} .1365-2664.2006 .01130 . x$

Goulson D (2003) Conserving wild bees for crop pollination. Food Agric Environ 1:142-144

Goulson D, Lye GC, Darvill B (2008) Diet breadth, coexistence and rarity in bumblebees. Biodivers Conserv 17:3269-3288. https:// doi.org/10.1007/s10531-008-9428-y

Goulson D, Nicholls E, Botias C, Rotheray EL (2015) Bee declines driven by combined stress from parasites, pesticides, and lack of flowers. Science 347:1255957. https://doi.org/10.1126/scien ce. 1255957

Goulson D, Thompson J, Croombs A (2018) Rapid rise in toxic load for bees revealed by analysis of pesticide use in Great Britain. PeerJ 6:e5255. https://doi.org/10.7717/peerj.5255

Grass I, Albrecht J, Jauker F et al (2016) Much more than bees-wildflower plantings support highly diverse flower-visitor communities from complex to structurally simple agricultural landscapes. Agric Ecosyst Environ 225:45-53. https://doi.org/10.1016/J. AGEE.2016.04.001

Gresty CEA, Clare E, Devey DS et al (2018) Flower preferences and pollen transport networks for cavity-nesting solitary bees: implications for the design of agri-environment schemes. Ecol Evol. https ://doi.org/10.1002/ece3.4234

Gruber B, Eckel K, Everaars J, Dormann CF (2011) On managing the red mason bee (Osmia bicornis) in apple orchards. Apidologie 42:564-576. https://doi.org/10.1007/s13592-011-0059-z

Hallmann CA, Sorg M, Jongejans E et al (2017) More than 75 percent decline over 27 years in total flying insect biomass in protected areas. PLoS ONE 12:e0185809. https://doi.org/10.1371/journ al.pone.0185809

Hanley ME, Franco M, Pichon S et al (2008) Breeding system, pollinator choice and variation in pollen quality in British herbaceous plants. Funct Ecol 22:592-598. https://doi.org/10.111 1/j.1365-2435.2008.01415.x

Heard MS, Carvell C, Carreck NL et al (2007) Landscape context not patch size determines bumble-bee density on flower mixtures sown for agri-environment schemes. Biol Lett 3:638-641. https ://doi.org/10.1098/rsbl.2007.0425

Hicks DM, Ouvrard P, Baldock KCR et al (2016) Food for pollinators: quantifying the nectar and pollen resources of urban flower meadows. PLoS ONE 11:e0158117. https://doi.org/10.1371/journ al.pone. 0158117

Hoehn P, Tscharntke T, Tylianakis JM, Steffan-Dewenter I (2008) Functional group diversity of bee pollinators increases crop yield. Proc Biol Sci 275:2283-2291. https://doi.org/10.1098/ rspb.2008.0405

Jacobs JH, Clark SJ, Denholm I et al (2009) Pollination biology of fruitbearing hedgerow plants and the role of flower-visiting insects in fruit-set. Ann Bot 104:1397-1404. https://doi.org/10.1093/aob/ mcp236

Johansen CA (1977) Pesticides and pollinators. Annu Rev Entomol $22: 177-192$
Nieto A, Roberts SP, Kemp J et al (2014) European red list of bees. Publication Office of the European Union, Luxembourg

Ollerton J, Erenler H, Edwards M, Crockett R (2014) Pollinator declines. Extinctions of aculeate pollinators in Britain and the role of large-scale agricultural changes. Science 346:1360-1362. https://doi.org/10.1126/science.1257259

Ouvrard P, Transon J, Jacquemart A-L (2018) Flower-strip agri-environment schemes provide diverse and valuable summer flower resources for pollinating insects. Biodivers Conserv. https://doi. org/10.1007/s10531-018-1531-0

Pollard E, Yates TJ (1993) Monitoring butterflies for ecology and conservation: the British butterfly monitoring scheme. Chapman \& Hall, London

R Core Team (2018) R: a language and environment for statistical computing. R Core Team, Vienna

Richards AJ (2001) Does low biodiversity resulting from modern agricultural practice affect crop pollination and yield? Ann Bot 88:165-172. https://doi.org/10.1006/anbo.2001.1463

Rollin O, Benelli G, Benvenuti S et al (2016) Weed-insect pollinator networks as bio-indicators of ecological sustainability in agriculture. A review. Agron Sustain Dev 36:8. https://doi.org/10.1007/ s13593-015-0342-x

Scheper J, Bommarco R, Holzschuh A et al (2015) Local and landscape-level floral resources explain effects of wildflower strips on wild bees across four European countries. J Appl Ecol 52:11651175. https://doi.org/10.1111/1365-2664.12479

Sheffield CS (2014) Pollination, seed set and fruit quality in apple: studies with Osmia lignaria (Hymenoptera: Megachilidae) in the Annapolis Valley, Nova Scotia, Canada. J Pollinat Ecol $12: 120-128$

Sutter L, Jeanneret P, Bartual AM et al (2017) Enhancing plant diversity in agricultural landscapes promotes both rare bees and dominant crop-pollinating bees through complementary increase in key floral resources. J Appl Ecol 54:1856-1864. https://doi. org/10.1111/1365-2664.12907

Underwood E, Darwin G, Gerritsen E (2017) Pollinator initiatives in EU Member States: success factors and gaps. Report for European Commission under contract for provision of technical support related to Target 2 of the EU Biodiversity Strategy to 2020maintaining and restoring ecosystems and their services ENV.B.2/ SER/2016/0018. Brussels

Uyttenbroeck R, Piqueray J, Hatt S et al (2017) Increasing plant functional diversity is not the key for supporting pollinators in wildflower strips. Agric Ecosyst Environ 249:144-155. https://doi. org/10.1016/J.AGEE.2017.08.014

Warnes GR, Bolker B, Bonebakker L, et al (2016) gplots: various R programming tools for plotting data. R Packag. version 3.0.1

Warzecha D, Diekötter T, Wolters V, Jauker F (2018) Attractiveness of wildflower mixtures for wild bees and hoverflies depends on some key plant species. Insect Conserv Divers 11:32-41. https:// doi.org/10.1111/icad.12264

Wickham H (2016) ggplot2: elegant graphics for data analysis. Springer-Verlag, New York

Williams NM, Lonsdorf EV (2018) Selecting cost-effective plant mixes to support pollinators. Biol Conserv 217:195-202. https://doi. org/10.1016/J.BIOCON.2017.10.032

Wood TJ, Holland JM, Goulson D (2015a) Pollinator-friendly management does not increase the diversity of farmland bees and wasps. Biol Conserv 187:120-126. https://doi.org/10.1016/J.BIOCO N.2015.04.022

Wood TJ, Holland JM, Hughes WOH, Goulson D (2015b) Targeted agri-environment schemes significantly improve the population size of common farmland bumblebee species. Mol Ecol 24:16681680. https://doi.org/10.1111/mec.13144 
Wood TJ, Holland JM, Goulson D (2017) Providing foraging resources for solitary bees on farmland: current schemes for pollinators benefit a limited suite of species. J Appl Ecol 54:323-333. https://doi. org/10.1111/1365-2664.12718

Woodcock BA, Edwards M, Redhead J et al (2013) Crop flower visitation by honeybees, bumblebees and solitary bees: behavioural differences and diversity responses to landscape. Agric Ecosyst Environ 171:1-8. https://doi.org/10.1016/J.AGEE.2013.03.005
Zhang H, Huang J, Williams PH et al (2015) Managed bumblebees outperform honeybees in increasing peach fruit set in china: different limiting processes with different pollinators. PLoS ONE 10:e0121143. https://doi.org/10.1371/journal.pone.0121143

Publisher's Note Springer Nature remains neutral with regard to jurisdictional claims in published maps and institutional affiliations. 